(C) Elsevier Sequoia S.A., Lausanne - Printed in The Netherlands

\title{
THE ELECTROCHEMISTRY OF GOLD IN ACID AQUEOUS SOLUTIONS CONTAINING CHLORIDE IONS
}

\author{
J. HERRERA GALlego, C.E. CASTELlaNo, A.J. CALANDR A and A.J. ARViA \\ Instituto de Investigaciones Fisicoquimicas Teóricas y Aplicadas, División Electroquimica, \\ Facultad de Ciencias Exactas, Universidad Nacional de La Plata, La Plata (Argentina)
}

(Received 10th September 1975)

\begin{abstract}
Results obtained with differently prepared gold electrodes in acid solutions containing chloride ion at temperatures ranging from 22 to $65^{\circ} \mathrm{C}$ are reported. Potentiostatic techniques and rotating disc electrodes were employed. The anodic dissolution, the onset of passivity and the cathodic deposition of the metal are investigated under different experimental conditions. The anodic dissolution of $\mathrm{Au}$ is discussed in terms of possible reaction mechanisms involving the participation of different adsorbed species. The onset of passivation is related to the depletion of chloride ion at the reaction interface. The experimental voltammograms can be reproduced by means of an equation which considers the diffusion of chloride ion, the activation polarization related to the dissolution of $\mathrm{Au}$ and the establishment of passivity.
\end{abstract}

\section{INTRODUCTION}

The electrochemistry of gold in aqueous solutions, particularly in the presence of complex-forming anions, such as $\mathrm{Cl}^{-}, \mathrm{Br}^{--}$and $\mathrm{CN}^{--}$, has been studied for a long time [ $1-8]$, because of its importance in gold refining, in gold plating, and more recently in circuit printing techniques. In spite of the great deal of work already made, data on the kinetics of gold electrode reactions are not altogether consistent. Thus, the participation of either soluble or adsorbed lower-valent gold species either as intermediates or as final products in the metal dissolution and in the passivation process and the role played by different adsorbed anions, such as $\mathrm{Cl}^{-}$ion, in these processes are not definitely established. The adsorption of traces of $\mathrm{Cl}^{-}$ion on gold in $0.2 \mathrm{M} \mathrm{H}_{2} \mathrm{SO}_{4}$ solution occurs in the potential region $-0.2 \mathrm{~V}$ to $1.8 \mathrm{~V}$ and it causes an increase in the amount of soluble gold produced during the anodic and cathodic parts of a potential cycle at the electrode [9]. The adsorbed $\mathrm{Cl}^{-}$ion apparently exists in two different states on a gold surface and is influenced by the crystal orientation of gold [10].

In $\mathrm{Cl}^{-}$ion containing solutions the anodic dissolution of gold occurs at potentials which are close to the potential where the metal passivation sets in, due to the formation of a thin oxide gold film $[11-13]$. The influence of the 
latter in the electrodissolution process is still uncertain. However, a competition of $\mathrm{Cl}^{-}$ion with oxygen for sites on gold has been postulated [3].

This paper reports the behaviour of gold electrodes in solutions containing $\mathrm{Cl}^{-}$ion under different conditions, covering the active dissolution and passivity regions, and the electrodeposition region.

\section{EXPERIMENTAL}

A conventional three compartment electrolysis cell was used. Two different rotating disc working electrodes embedded in Teflon rods were employed: (i) a gold (J. Matthey, spectroscopic quality) electrode $\left(0.124 \mathrm{~cm}^{2}\right)$; (ii) a goldplated gold electrode $\left(0.071 \mathrm{~cm}^{2}\right)$. Occasionally spectroscopic quality gold wire electrodes were used. The counter-electrode was a $2.5 \mathrm{~cm}^{2}$ platinum sheet. A saturated calomel electrode was the reference electrode. All potentials are reported vs. the SCE. Before each run the working electrodes were mirror polished with fine grain alumina suspension in ethanol.

Solutions were prepared with triple distilled water and A.R. chemicals. The composition employed is $x \mathrm{HCl}+y \mathrm{NaCl}+z \mathrm{HAuCl}_{4} \cdot 3 \mathrm{H}_{2} \mathrm{O}+1 \mathrm{M} \mathrm{NaClO}_{4}$, where $5 \times 10^{-3} \leqslant x \leqslant 1 M ; 5 \times 10^{-3} \leqslant y \leqslant 1 M ; 0 \leqslant z \leqslant 1.2 \times 10^{-2}$ and $0.5 \leqslant \mathrm{pH} \leqslant 7$. Experiments were made from 22 to $65^{\circ} \mathrm{C}$. The viscosity and specific gravity of solutions were determined as usual.

The device to drive the RDE is described elsewhere [14]. The $E / I$ curves were recorded under potentiostatic conditions, either stationary or potentiodynamically, employing a triangular potential scan. Conventional coulometry was performed to determine the anodic dissolution yield of gold.

\section{RESULTS}

Potentiodynamic E/I curves run with a single symmetric triangular potential scan

When a gold electrode is anodized in hydrochloric acid solutions various electrochemical reactions occur, depending on the applied potential. Thus, at potentials between 0.4 and $1.1 \mathrm{~V}$ gold electrodissolution takes place; at ca. $1.5 \mathrm{~V}$ a net oxygen evolution is observed and at potentials comprised between those values, gold oxide films are formed. At ca. $0.99 \mathrm{~V}$ gold dissolution occurs principally as Au(III) in good agreement with previous coulometric data $[2,3,15]$. The $\mathrm{Au}(\mathrm{III})$ concentration in solution increases during repetitive potential scanning.

A blank run, with a gold electrode in a $1 \mathrm{M} \mathrm{NaClO}_{4}$ solution covering from +1.5 to $-1.5 \mathrm{~V}$, involves respectively at these extreme potentials, a net oxygen evolution and a net hydrogen evolution. In the region preceding molecular oxygen formation where the electrochemical oxidation of the gold surface takes place the maximum anodic current is about $25 \mu \mathrm{A}$. The electrochemical reduction of the surface oxide occurs at potentials lower than $0.9 \mathrm{~V}[13,16]$. 


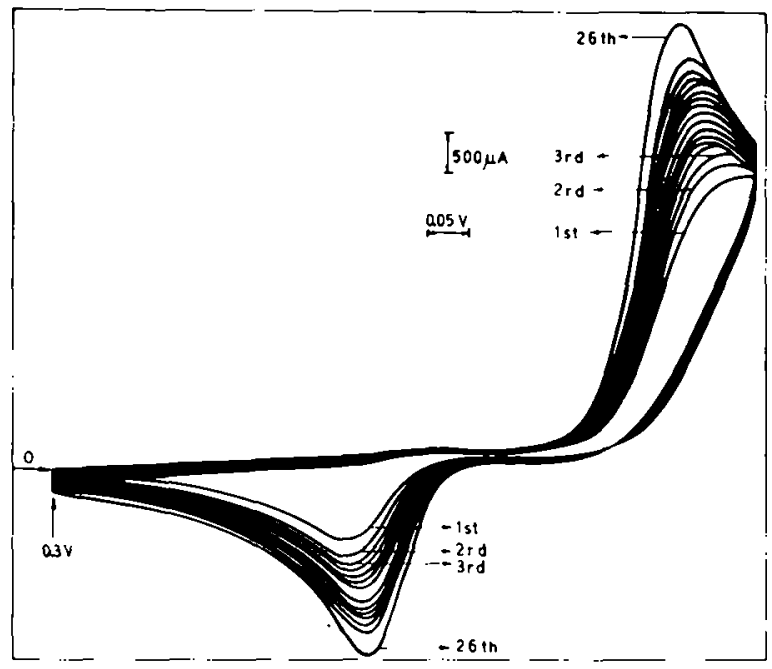

Fig. 1. Voltammograms run with repetitive triangular potential sweeps at $150 \mathrm{mV} \mathrm{s}^{-1}$. $3.04 \times 10^{-2} M \mathrm{HCl}, 1 M \mathrm{NaClO}_{4}, 25^{\circ} \mathrm{C}$.

Reproducible potentiodynamic $E / I$ profiles run with $x M \mathrm{HCl}+1 \mathrm{M} \mathrm{NaClO}_{4}$ solutions are only obtained after the gold electrode is activated with repetitive potential cycling between 0.3 and $1.17 \mathrm{~V}$, at $50-200 \mathrm{mV} \mathrm{s}^{-1}$, started towards the anodic direction (Fig. 1). Stable and reproducible $E / I$ displays are obtained after 30 potential scans between 0.3 and $1.17 \mathrm{~V}$, at $150 \mathrm{mV} \mathrm{s}^{-1}$. Then, the anodic and cathodic current peaks become better defined and the former being located at potentials more cathodic than those corresponding to earlier cycles. The anodic current corresponds to the electrodissolution of gold and the cathodic current to the electrodeposition of the dissolved metal. A deposit of gold can be separated by rubbing the activated electrodes with a filter paper. Cleaned electrodes exhibited the $E / I$ characteristics of the unactivated electrodes. The electrode activation is apparently related to surface changes which assist the heterogeneous chemical processes involved in the electrode reaction.

The anodic potential scan run between $0.3 \mathrm{~V}$ and $1.17 \mathrm{~V}$ (Fig. 2a), exhibits only the anodic current peak of the active dissolution of gold and that related to its electrodeposition. However, it can be shown that the cathodic $E / I$ curves run within this potential region exhibit either one or two cathodic current peaks depending on the amplitude of the potential sweep and on the $\mathrm{Cl}^{-}$ion concentration in solution. Two cathodic current peaks are seen when the anodic potential limit is lower than the anodic peak potential (Fig. 3). The same occurs at high $\mathrm{Cl}^{-}$ion concentration (Figs. 3a,b). The cathodic current peak at $0.66 \mathrm{~V}$ corresponds to the electrodeposition of $\mathrm{Au}$ from $\mathrm{AuCl}_{4}^{-}$as the peak height increases with its concentration.

On increasing the temperature the anodic current peak height increases and the peak potential becomes more cathodic. In general, the voltammograms approach a more reversible shape as temperature increases. 


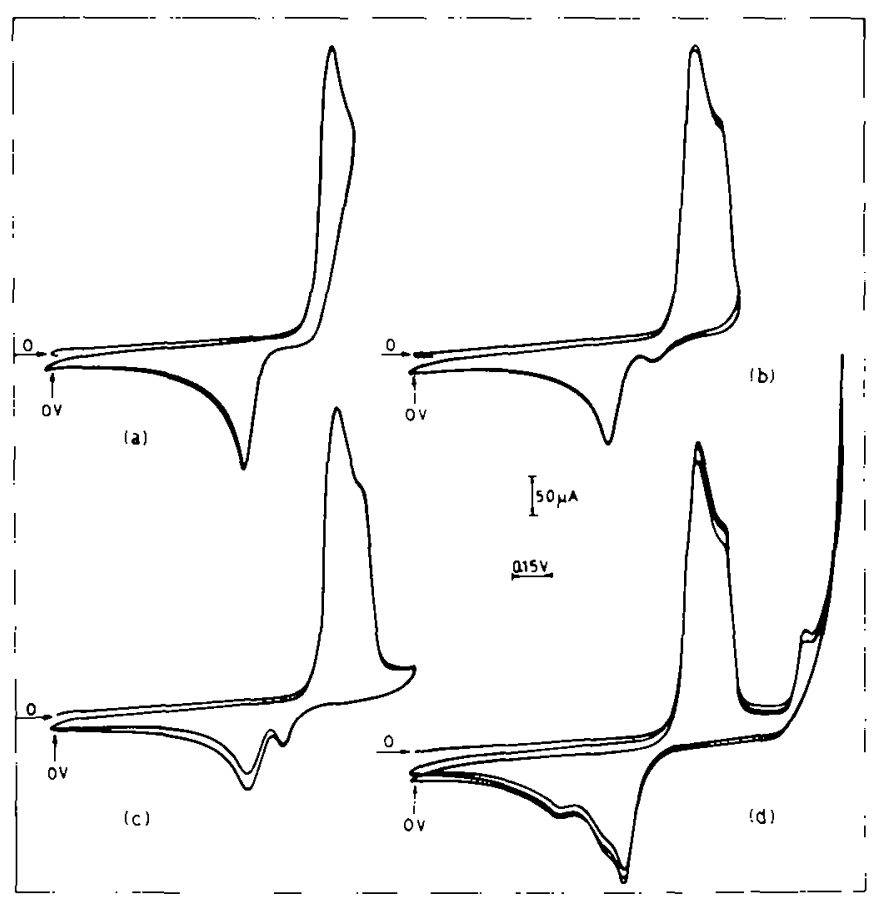

Fig. 2. Voltammograms covering different potential amplitudes at $\iota_{\mathrm{a}}=v_{\mathrm{c}}=100 \mathrm{mV} \mathrm{s}^{-1}$. $1.18 \times 10^{-2} \mathrm{MHCl}, 1 \mathrm{M} \mathrm{NaClO} 4,25^{\circ} \mathrm{C}$.

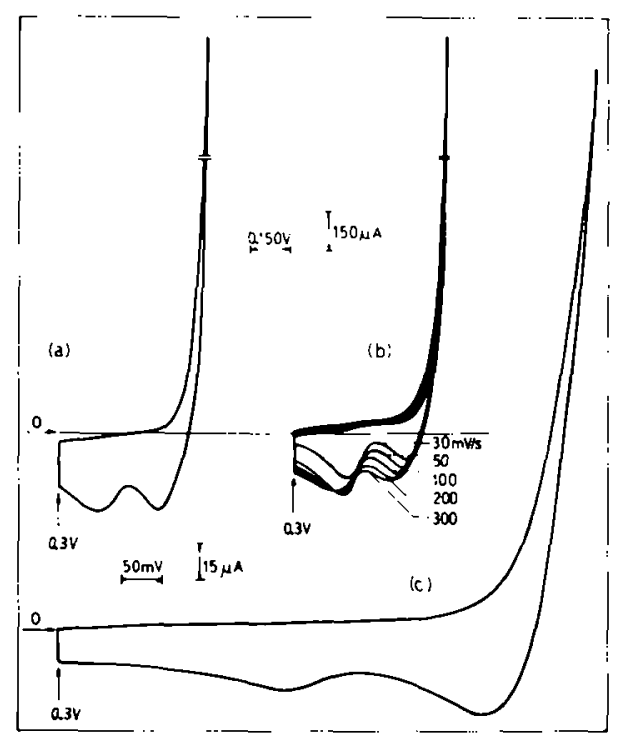

Fig. 3. Voltammograms run at different $v$. (a) $v_{\mathrm{a}}=v_{\mathrm{c}}=100 \mathrm{mV} \mathrm{s}{ }^{-1}$; (b) $v_{\mathrm{a}}=100 \mathrm{mV} \mathrm{s} \mathrm{s}^{-1}$ and different $v_{\mathrm{c}}, 2 \mathrm{M} \mathrm{HCl}, 1 \mathrm{M} \mathrm{NaClO}_{4}, 26^{\circ} \mathrm{C} ;$ (c) $v_{\mathrm{a}}=v_{\mathrm{c}}=100 \mathrm{mV} \mathrm{s}^{-1}, 0.1 \mathrm{M} \mathrm{NaCl}$, $1 \mathrm{M} \mathrm{NaClO}_{4}, 23.8^{\circ} \mathrm{C}$. 
When the anodic potential scan extends up to $1.65 \mathrm{~V}$, a net passivation sets in (Figs. 2 b,d). The $E / I$ profiles show a net anodic current peak, an abrupt current decrease at $1.2 \mathrm{~V}$ and a smooth inflexion at about $1.5 \mathrm{~V}$. The returning potential scan consists at least of two cathodic current peaks at 0.6 and $0.9 \mathrm{~V}$. Oxygen, if present, is electrochemically reduced at higher cathodic potentials than those related respectively to the surface oxide reduction $(0.9 \mathrm{~V})$ and to gold electrodeposition $(0.6 \mathrm{~V})$. The characteristics of the complementary cathodic potential scan depend of the anodic potential limit reached during the anodic scan. Thus, when the latter extends beyond $1.3 \mathrm{~V}$, two cathodic current peaks are observed at 0.9 and $0.7 \mathrm{~V}$. The cathodic peak height at $0.9 \mathrm{~V}$ in. creases markedly when the oxygen evolution region is reached, while the height of the other remains practically unaltered.

At a constant $\mathrm{Cl}^{-}$ion concentration a change of $\mathrm{pH}$ between 0.5 and 7 produces no appreciable modification of the potentiodynamic $E / I$ curve in the active dissolution region but only a shift of the potential where passivity sets in.

Degree of reversibility of the anodic dissolution reaction. Influence of the initial potential on the $E / I$ profile

The degree of reversibility of the anodic dissolution, as deduced from the voltammetric data depends to a great extent on the state of the metal surface The $E / I$ profile run with an activated electrode from an initial potential, $E_{\mathrm{i}}$, higher than that corresponding to the cathodic electrodeposition of gold (Fig. 4a), exhibits a notoriously irreversible anodic current peak. Thus, the initial portions of the anodic voltammograms run at different $v$ are coincident

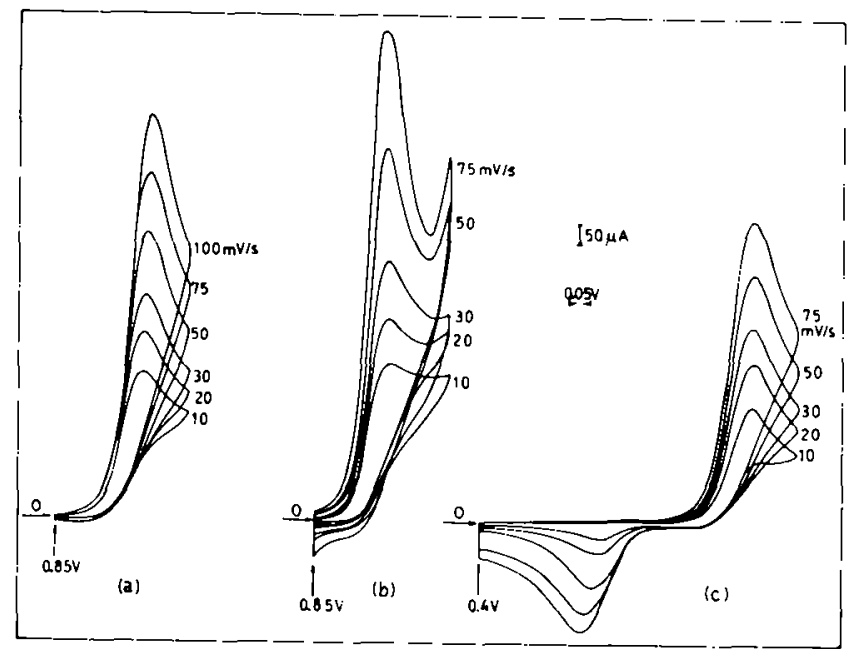

Fig. 4. Voltammograms run at different electrolysis time. $3.04 \times 10^{-2} \mathrm{M} \mathrm{HCl,} 1 \mathrm{M} \mathrm{NaClO}_{4}$, $25^{\circ} \mathrm{C}$. (a) $2 \mathrm{~min}$ anodization time at $1.0 \mathrm{~V}$; (b) 5 min cathodization time at $0.3 \mathrm{~V}$; (c) single triangular potential scan without previous electrolysis. 
while the potentials of the anodic current peaks become more anodic as $v$ increases. On the other hand, the $E / I$ characteristics obtained with fresh goldplated gold electrodes from either at 0.4 or at $0.85 \mathrm{~V}$ upwards (Figs. $4 \mathrm{a}, \mathrm{c}$ ), attain a more reversible shape. Their initial portions spread on the $E / I$ plane accordingly with $v$. The actual area of gold-plated gold electrodes, however, is appreciably larger than that of polished wire electrodes as deduced from the anodic charge related to the gold surface oxidation at ca. $1.13 \mathrm{~V}$.

E/I profiles obtained with single symmetric trapezoidal potentiodynamic scans

$E / I$ profiles recorded at $v_{\mathrm{a}}=v_{\mathrm{c}}$ but keeping the anode potential constant at $1.3 \mathrm{~V}$ for a time $\tau(0 \leqslant \tau \leqslant 1 \mathrm{~min})$ elapsed between the anodic and the cathodic scans are seen in Fig. 5. As $\tau$ decreases, the cathodic potential scan exhibits an increasing anodic current, the cathodic charge related to gold oxide reduction decreases and the cathodic current related to Au(III) increases. This indicates a competition between a passivation and a depassivation effect. The current peak height related to $\mathrm{Au}$ electroreduction decreases as $\tau$ increases due to a decrease of $\mathrm{Au}($ III) concentration at the interface.

Anodic potentiostatic E/I curves with gold rotating disc electrodes

Anodic potentiostatic $E / I$ curves run with gold RDE, from 0.3 to $1.82 \mathrm{~V}$, at $5 \mathrm{mV} \mathrm{s}^{-1}$ and different rotation speeds, $\omega$, exhibit an active dissolution up to $1.17 \mathrm{~V}$ and a passive region from 1.17 to $1.9 \mathrm{~V}$. In the former region the $E / I$ curves (Fig. 6), approach a limiting current. Both, the current read at $1.17 \mathrm{~V}$ and the limiting current increase linearly with $\omega^{1 / 2}$. At a constant $\omega$, the anodic limiting current depends linearly on the $\mathrm{HCl}$ concentration (Fig. 7).

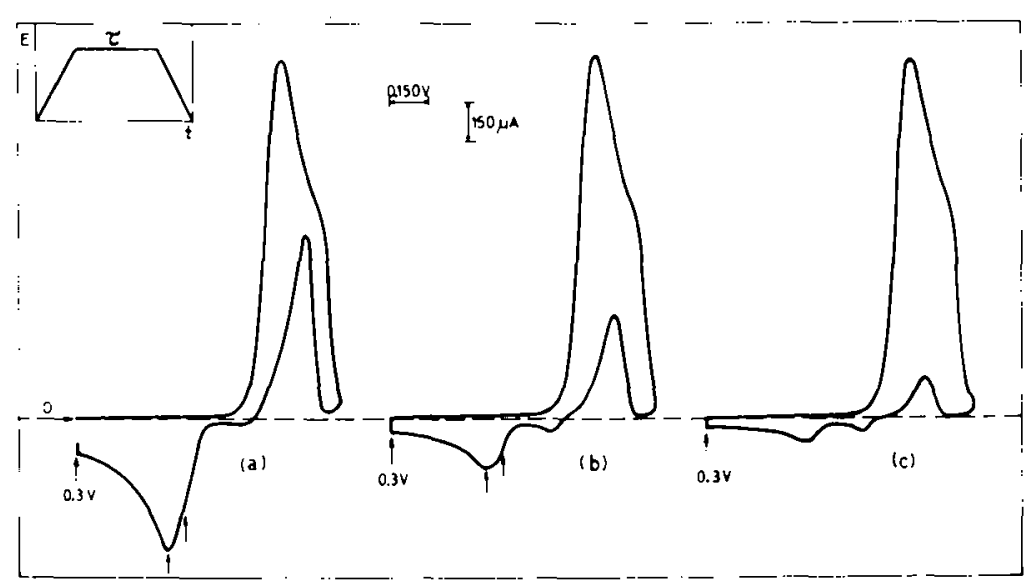

Fig. 5. Voltammograms run with a trapezoidal potential scan. $E_{\mathrm{i}}=0.3 \mathrm{~V}, v_{\mathrm{a}}=v_{\mathrm{c}}=100 \mathrm{mV}$ $\mathrm{s}^{-1}, 5.15 \times 10^{-2} \mathrm{M} \mathrm{HCl}, 1 \mathrm{M} \mathrm{NaClO}_{4}, 25^{\circ} \mathrm{C}$. (a) $\tau=0$, (b) $\tau=30 \mathrm{~s}$, (c) $\tau=60 \mathrm{~s}$. 


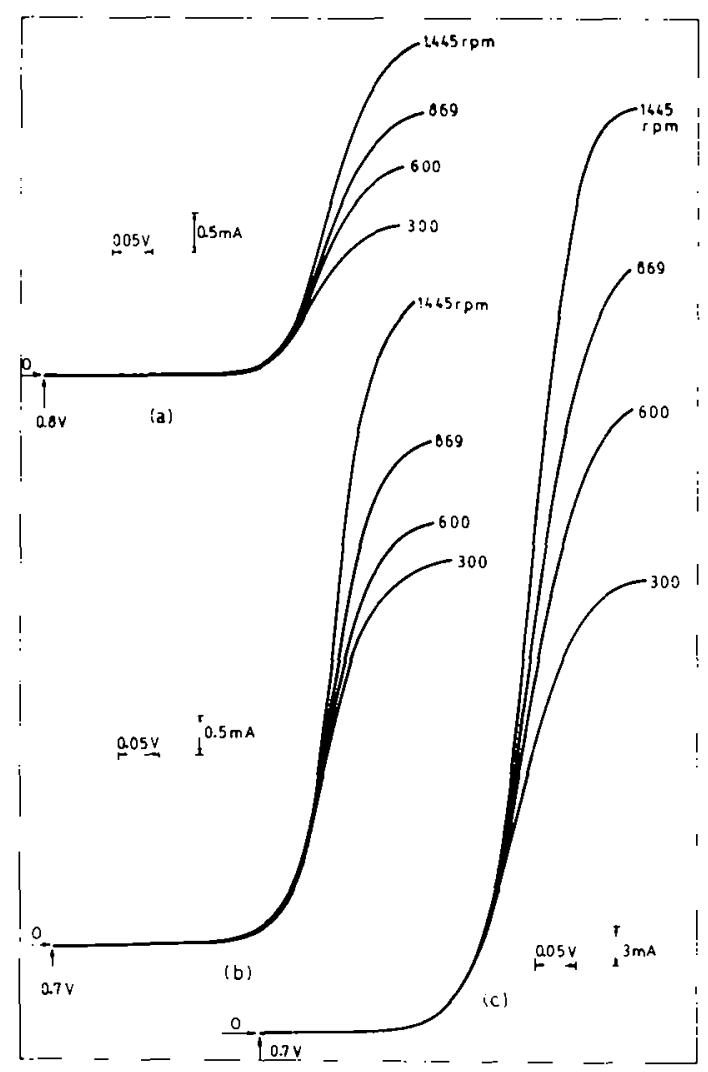

Fig. 6. Anodic $E / l$ curves run with a $\mathrm{RDE}$ at $5 \mathrm{mV} \mathrm{s}^{-1}$ at different rotation speeds. $x M \mathrm{NaCl}, 3.2 \times 10^{-1} M \mathrm{HCl}, 1 M \mathrm{NaClO}_{4}, 23.8^{\circ} \mathrm{C}$. (a) $x=5 \times 10^{-2}$; (b) $x=10^{-1}$; (c) $x=1$.

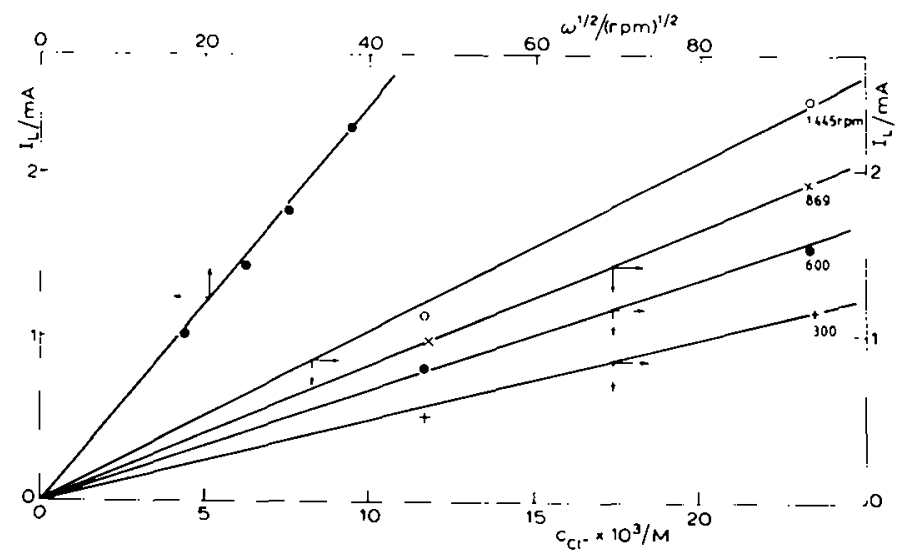

Fig. 7. $\left(I_{\mathrm{L}}\right)_{\mathrm{a}}$ vs. $(\omega)^{1 / 2}$ plot, $2.35 \times 10^{-2} \mathrm{M} \mathrm{HCl}, 1 \mathrm{M} \mathrm{NaClO}_{4}, 26^{\circ} \mathrm{C}$ and $\left(I_{\mathrm{L}}\right)_{\mathrm{a}}$ vs. $c_{\mathrm{HCl}}$ plot at different $\omega$ and $26^{\circ} \mathrm{C}$. 
The potential characterizing the passive state is apparently independent of $\omega^{1 / 2}$.

At low $v$ the $\mathrm{Cl}^{-}$ion concentration at the interface is replenished during rotation so that the $E / I$ profile presents no appreciable hysteresis. However, at the highest $v$, the $E / I$ profiles approach those obtained with the solution at rest.

\section{E/I profiles run with asymmetric triangular potential sweeps}

Voltammograms run between 0.3 and $1.18 \mathrm{~V}$ at $v_{\mathrm{a}}=100 \mathrm{mV} \mathrm{s}^{-1}$ and $30 \leqslant v_{c} \leqslant 500 \mathrm{mV} \mathrm{s}^{-1}$ (Fig. 8b) show that the amount of Au(III) which is reduced during the cathodic scan depends on $v_{c}$, that is on the time elapsed to sweep the potential region comprised between the anodic potential limit and the beginning of the reduction process. The potential related to the cathodic current peak remains practically unchanged with $v_{c}$, while the initial

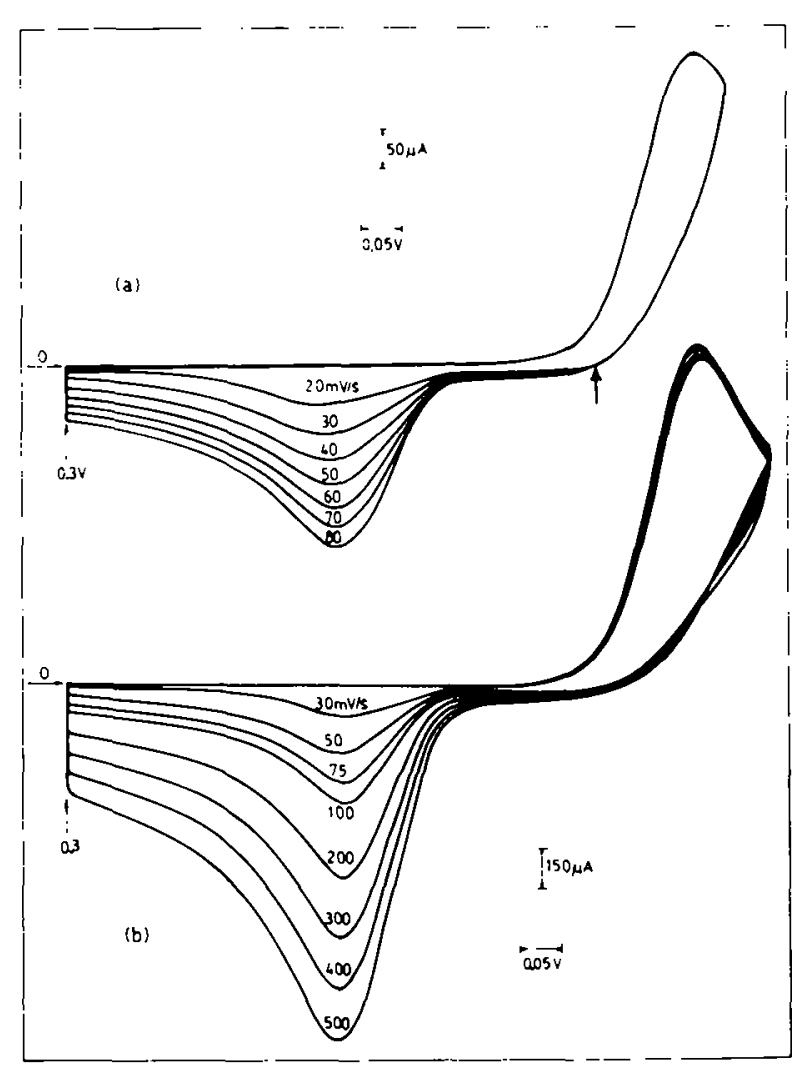

Fig. 8. Voltammograms run at $v_{\mathrm{a}} \neq v_{\mathrm{c}}$. (a) $v_{\mathrm{a}}=30 \mathrm{mV} \mathrm{s}^{-1}, 2.54 \times 10^{-2} \mathrm{M} \mathrm{HCl}, 1 M$ $\mathrm{NaClO}_{4}, 24.8^{\circ} \mathrm{C}$. The arrow indicates the instant where the cathodic potential scanning rate is changed. (b) $v_{\mathrm{a}}=100 \mathrm{mV} \mathrm{s}^{-1}, 5.15 \times 10^{-2} \mathrm{M} \mathrm{HCl}, 1 M \mathrm{NaClO}_{4}, 24.8^{\circ} \mathrm{C}$. The potential sweep rate is changed at the anodic potential extreme. 


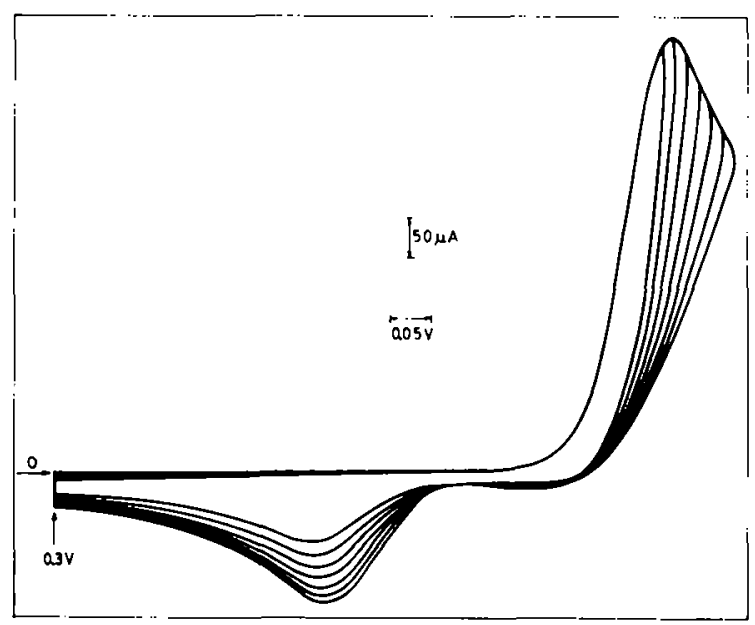

Fig. 9. Triangular single sweep voltammograms run at $v_{\mathrm{a}}=v_{\mathrm{c}}=50 \mathrm{mV} \mathrm{s}^{-1}$ covering different potential amplitudes. $2.54 \times 10^{--2} \mathrm{M} \mathrm{HCl}, 1 M \mathrm{NaClO}_{4}, 25^{\circ} \mathrm{C}$.

portions of the corresponding $E / I$ profiles are separated. These experiments are confirmed by changing $v_{\mathrm{c}}$ just at the instant when the potential reaches the point corresponding to the null net current (Fig. 8a).

Effect of the amplitude of the potential scan on the cathodic current peak

Potentiodynamic runs from $0.3 \mathrm{~V}$ upwardly at $50 \mathrm{mV} \mathrm{s}^{-1}$ (Fig. 9) with anodic potential limit varied from $1.085 \mathrm{~V}$ up to the passivity potential, show that the cathodic current peak height increases and becomes more anodic with the increasing anodic potential limit. Thus, the larger the amount of oxidation product the more positive the potential of the cathodic current peak is. When the amount of anodic product diminishes (lower anodic potential limit) a second cathodic current peak appears at ca. $0.91 \mathrm{~V}$.

\section{E/I profiles run towards cathodic potentials}

Single cathodic potential sweeps run from $0.8 \mathrm{~V}$ towards cathodic potentials with an electrolytic solution containing $\mathrm{AuCl}_{4}^{-}$ion (Fig. 10) exhibit only the cathodic current peak at ca. $0.65 \mathrm{~V}$ which depends on $v$. The effect of potential cycling is also shown in the Figure.

\section{INTERPRETATION OF RESULTS}

The potential region of gold electrodissolution and electrodeposition

Potentiodynamic runs within the temperature $\left(25\right.$ to $\left.65^{\circ} \mathrm{C}\right)$ and concentration ( $5 \times 10^{-3} M$ to $1 M$ ) ranges investigated, show that either for activated 


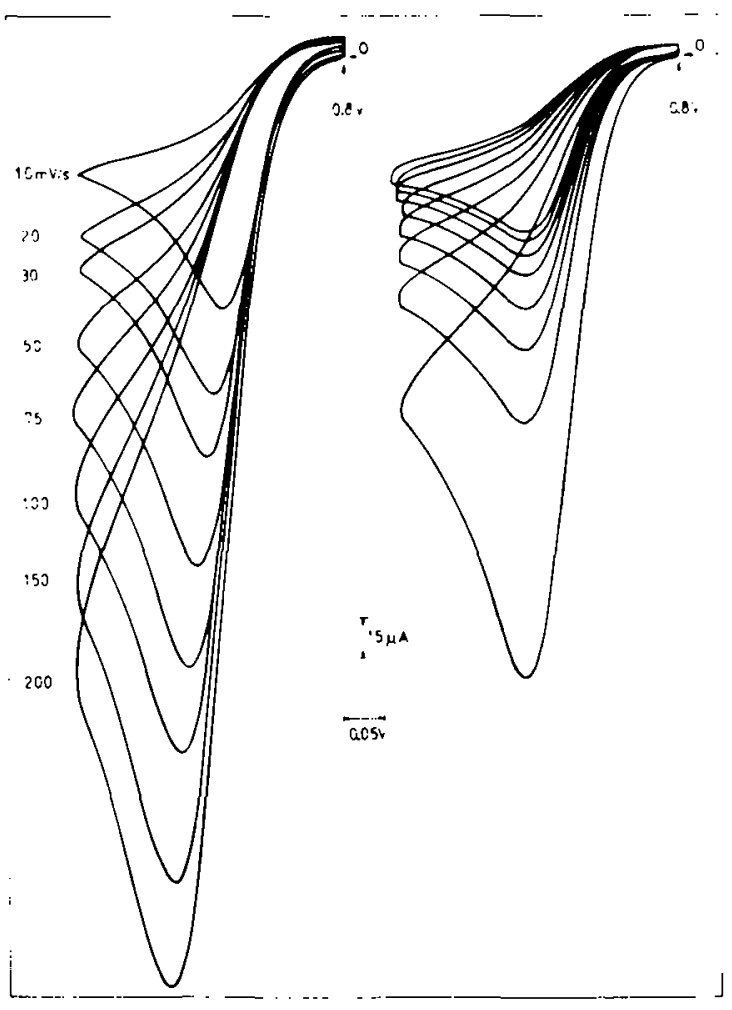

Fig. 10. Voltammograms run in the cathodic direction. $5.30 \times 10^{-12} . \mathrm{H} \mathrm{HCl}, 1.20 \times 10^{-3} . \mathrm{H}$ $\mathrm{HAuCl}_{4}, 1 . \mathrm{M} \mathrm{NaClO}_{4}, 26.2^{\mathrm{n}} \mathrm{C}$. (a) Effect of $l_{c} ;$ (b) repetitive triangular potential scans at $75 \mathrm{mVs}-1$.

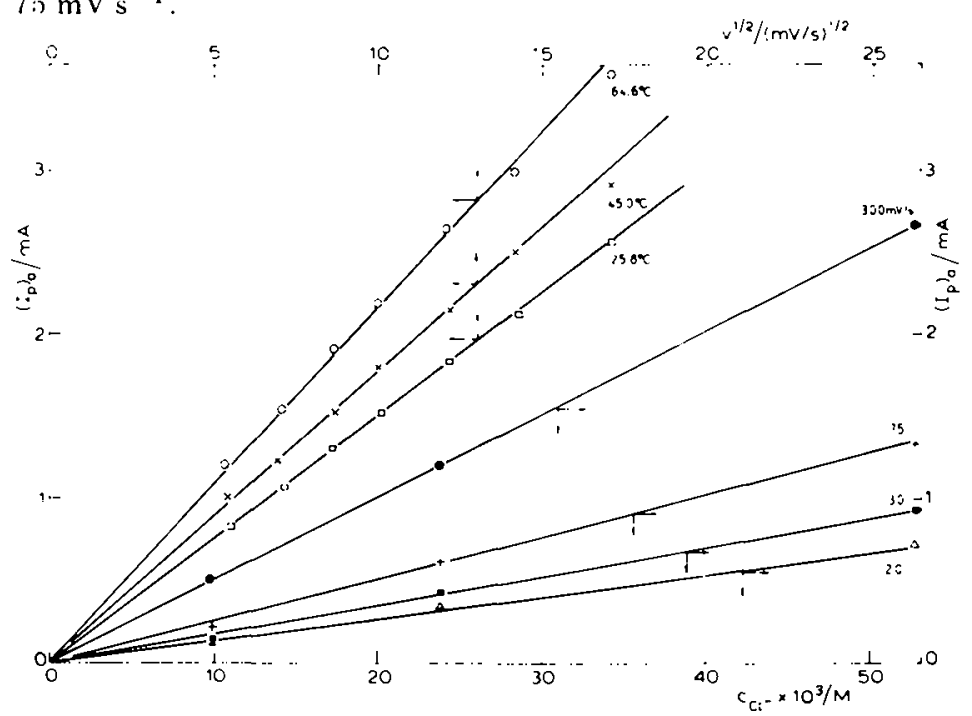

Fig. 11. $\left(I_{\mathrm{p}}\right)_{\mathrm{a}}$ vs. $(v)^{1 / 2}$ plots at different temperatures, $5.3 \times 10^{-2} . \mathrm{M} \mathrm{HCl}, 1 \mathrm{M} \mathrm{NaClO}_{4}$ and $\left(I_{\mathrm{p}}\right)_{\mathrm{a}}$ vs. $c_{\mathrm{HCl}}$ plots at $25^{\circ} \mathrm{C}$ and different $v$. 

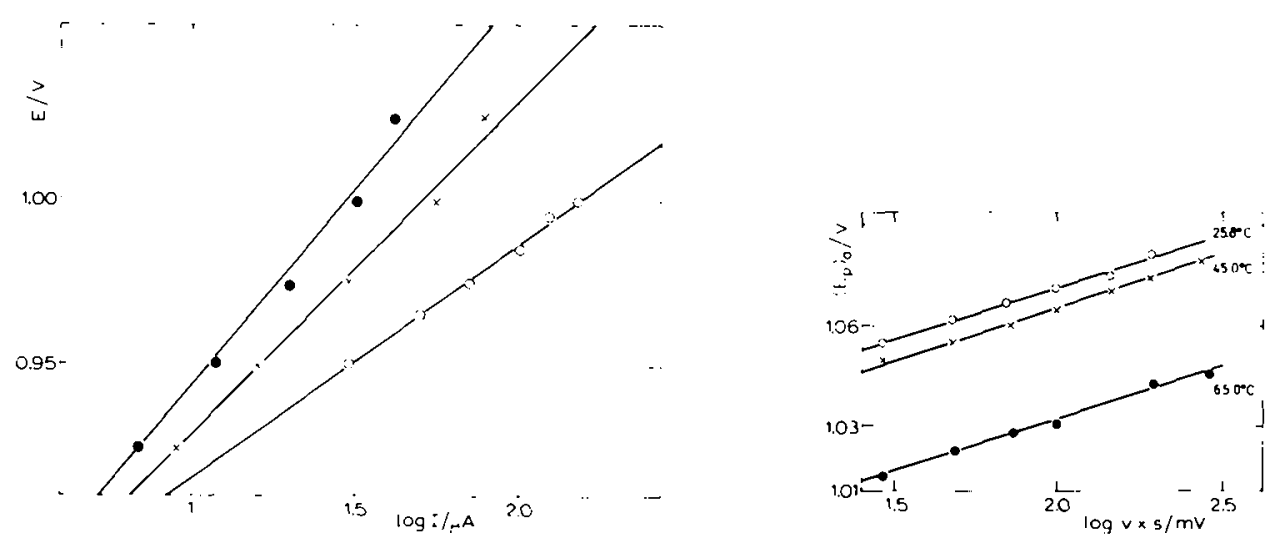

Fig. 12. E/log $I$ plots of the initial portions of the anodic voltammograms, $5.3 \times 10^{-2} .1 \mathrm{H}$ $\mathrm{HCl}, 1 . \mathrm{M} \mathrm{NaClO}{ }_{4}, 25$ C. (๑) First sweep; (x) intermediate sweep; (C) steady reversible behaviour, $3.04 \times 10^{-2} \mathrm{M} \mathrm{HCl}, 1 . M \mathrm{NaClO}_{4}, 25^{\circ} \mathrm{C}$.

Fig. 13. $\left(E_{\mathrm{p}}\right)_{\mathrm{a}}$ vs. $\log \mathrm{e}$ plots at different temperatures, $5.3 \times 10^{-2}: 1 \mathrm{HCl}, 1 \mathrm{M} \mathrm{NaClO}_{4}$.

or non activated electrodes the height of the anodic current peak, $\left(I_{\mathrm{p}}\right)_{\mathrm{a}}$, depends linearly on $v^{1 / 2}$ and, at a constant temperature, the slopes of the straight lines depend linearly on the $\mathrm{HCl}$ concentration (Fig. 11). The temperature dependence of $\left(I_{p}\right)_{a}$ fits an Arrhenius equation, with an apparent activation energy equal to $7.5 \mathrm{~kJ} \mathrm{~mol}^{-1}\left(1.8 \mathrm{kcal} \mathrm{mol}^{-1}\right)$.

The initial portions of the anodic $E / I$ profiles corresponding to the activated electrode, are independent of $\mathrm{AuCl}_{4}^{-}$addition and yield linear $E / \log I$ plots with slopes close to $2.3(R T / F) \mathrm{V} /$ decade (Fig. 12), which are independent on $v_{\mathrm{a}}$. The peak potential, $\left(E_{\mathrm{p}}\right)_{\mathrm{a}}$, depends linearly on $\log v$, the slope of the straight line being close to $2.3\left(R^{\prime} T / F\right) \mathrm{V} /$ decade (Fig. 13).

'The degree of reversibility of gold anodes approaches two limiting situations. On a fresh gold surface the reaction behaves reversibly, namely $\left(E_{\mathrm{p}}\right)_{\mathrm{a}}$ is independent on $v$ and the anodic current peak, at any constant potential, changes linearly with $v^{1 / 2}$ (Fig. 14). On the other hand, when the electrode: surface is previously anodized $\left(E_{\mathrm{p}}\right)_{\mathrm{a}}$ changes linearly with $\log v$ and the initial portions of the $E / I$ curves are coincident. The change from one case to another apparently operates continuously with the potential cycling (Fig. 12) as it is seen through the change of the slope of the corresponding $E / \log I$ plots of the initial portion of the anodic voltammograms. Thus, the first scan gives a linear plot over a range of $0.15 \mathrm{~V}$ with a slope equal to $2.3(2 R T / F) \mathrm{V} / \mathrm{de}$ cade, while the following cycles approach the slope equal to $2.3(R T / F) \mathrm{V} / \mathrm{de}$ cade.

The anodic $E / I$ curves obtained with gold RDF at $2 \mathrm{mV} \mathrm{s}^{-1}$ fit linear $E / \log I$ plots at potentials lower than the apparent half-wave potential. The whole anodic $E / I$ curve can be linearized within a potential range of $0.11 \mathrm{~V}$ by plotting $E$ vs. $\log \left[\left(I_{\mathrm{L}}-I\right) / I\right]$ (Fig. 15), where $I_{\mathrm{L}}$ is the extrapolated limiting 


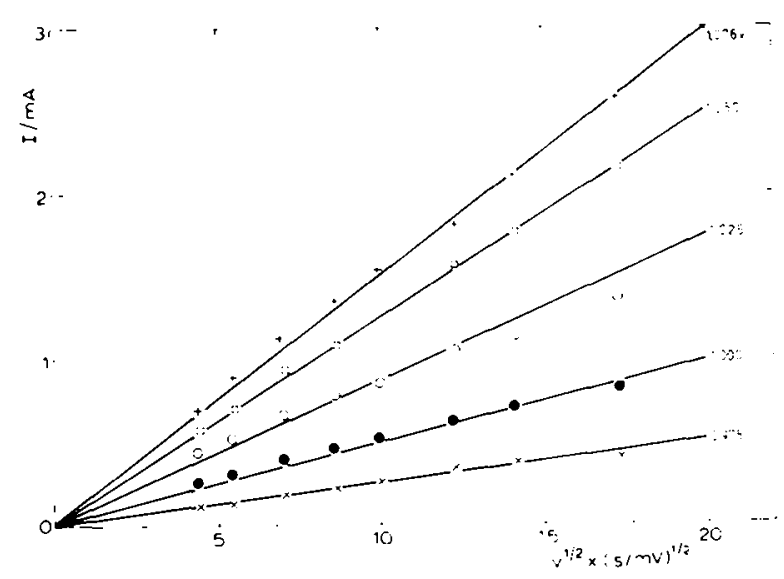

Fig. 14. Dependence of the anodic current on (1. $)^{1 / 2}$ at different potentials as indicated in the figure. $5.3 \times 10^{-2} .11 \mathrm{HCl}, 1 \mathrm{M} \mathrm{NaCiO}_{4}, 25.8 \mathrm{C}$.

current. At any rotation speed and $\mathrm{Cl}^{-}$ion concentration, the slopes of the straight lines are close to the $2.3(R T / F) \mathrm{V}$ /decade.

The RDF data indicate that the rate of gold electrodissolution in $\mathrm{Cl}^{--}$ion containing solutions fits, within the concentration range investigated, a 1 st order dependence with respect to $\mathrm{Cl}^{-}$ion concentration (Fig. 16) instead of a 2 nd order dependence as it has been claimed [2]. The separation between the anodic and the cathodic current peaks observed in the potential region of gold electrodissolution and electrodeposition, increases with the $\mathrm{Cl}^{-}$ion concentration and concomitantly, the anodic to cathodic charge ratio increases.

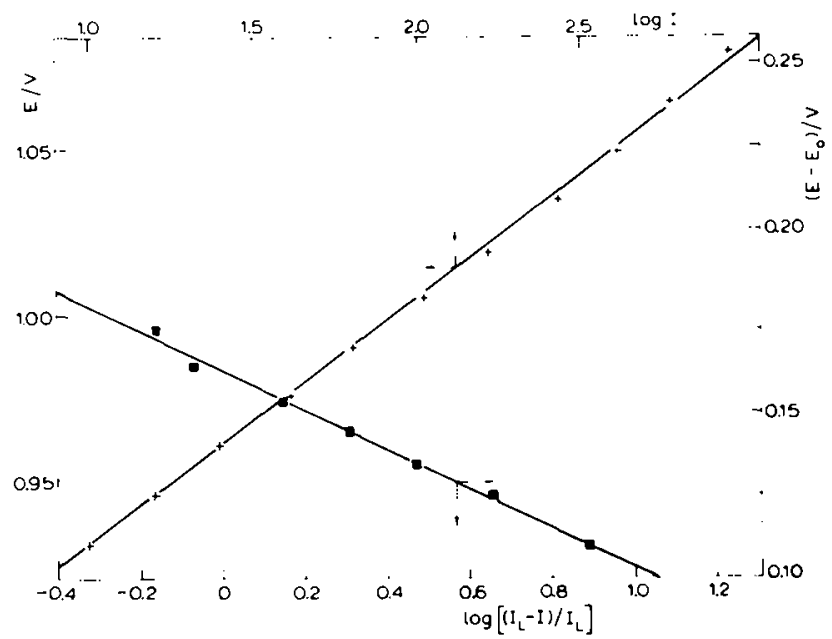

Fig. 15. $E / \log I$ and $E / \log \left[\left(I_{\mathrm{L}}-I\right) / I_{\mathrm{L}}\right]$ plots. $\left(-1445 \mathrm{rpm}, 2.54 \times 10^{-2} .1 / \mathrm{HCl}, 1 M\right.$ $\mathrm{NaClO}_{4}, 25^{\circ} \mathrm{C} ;(+) 2.35 \times 10^{-2} \mathrm{M} \mathrm{HCl}, 1: 1 / \mathrm{NaClO}_{4}, 25^{\circ} \mathrm{C}$. 


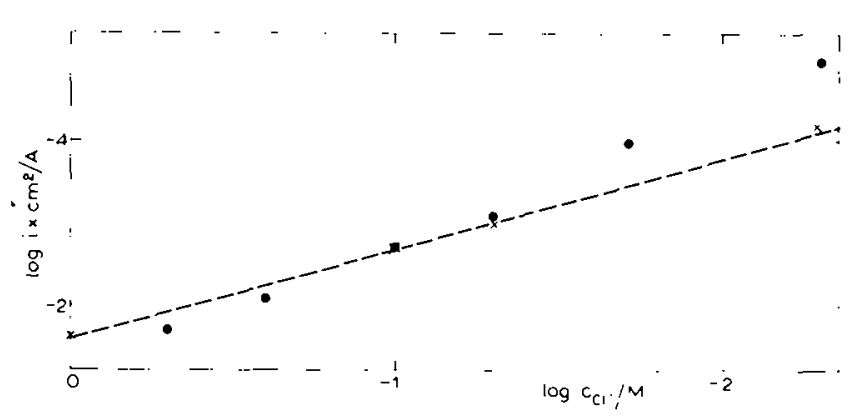

Fig. 16. Dependence of the anodic limiting current density on chloride ion concentration. (x) Present work, $E=0.975 \mathrm{~V}$; $(\bullet)$ from ref. [2], $E^{\prime}=0.978$ V. $25 \mathrm{C}$.

There is, therefore, a net loss of the anodic dissolution product by diffusion out of the interface into solution during the triangular potential scanning. When $v_{\mathrm{c}}$ increases, a larger amount of anodic product is picked up during the cathodic potential scan. Therefore, as $v_{c} \rightarrow \infty$ the total amount of anodic product should be reduced at the electrode. Unfortunately, the accurate evaluation of the total charge involved in the cathodic process is uncertain because of the smooth slope of the cathodic $E / I$ profile at potentials more negative than the cathodic peak potential. However, the $Q_{a} / Q_{c}$ ratio can be evaluated from the corresponding current peak height.

The cathodic $E / I$ profiles run with solutions containing $\mathrm{AuCl}_{4}^{-}$ion yield a linear $\left(I_{\mathrm{p}}\right)_{\mathrm{c}}$ vs. $v_{\mathrm{c}}^{1 / 2}$ plot and the cathodic peak potential, $\left(E_{\mathrm{p}}\right)_{\mathrm{c}}$, becomes more negative on increasing $v$. A linear $\left(E_{\mathrm{p}}\right)_{\mathrm{c}}$ vs. $\log v$ relationship is obtained (Fig. 17) whose slope is close to $2.3(R T / F) \mathrm{V} /$ decade. The cathodic $E / I$ pro-

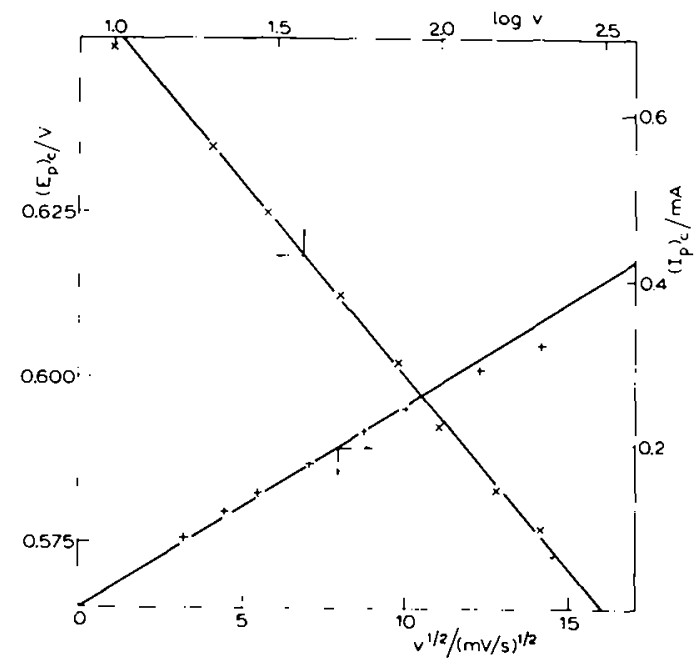

Fig. 17. $\left(I_{\mathrm{p}}\right)_{\mathrm{c}}$ vs. $(v)^{1 / 2}$ and $\left(E_{\mathrm{p}}\right)_{\mathrm{c}}$ vs. $\log v$ plots at $25.2^{\circ} \mathrm{C} .5 .30 \times 10^{-2} \mathrm{M} \mathrm{HCl}, 1.20 \times 10^{-3}$ $M \mathrm{HAuCl}_{4}, 1 M \mathrm{NaClO}_{4}$. 


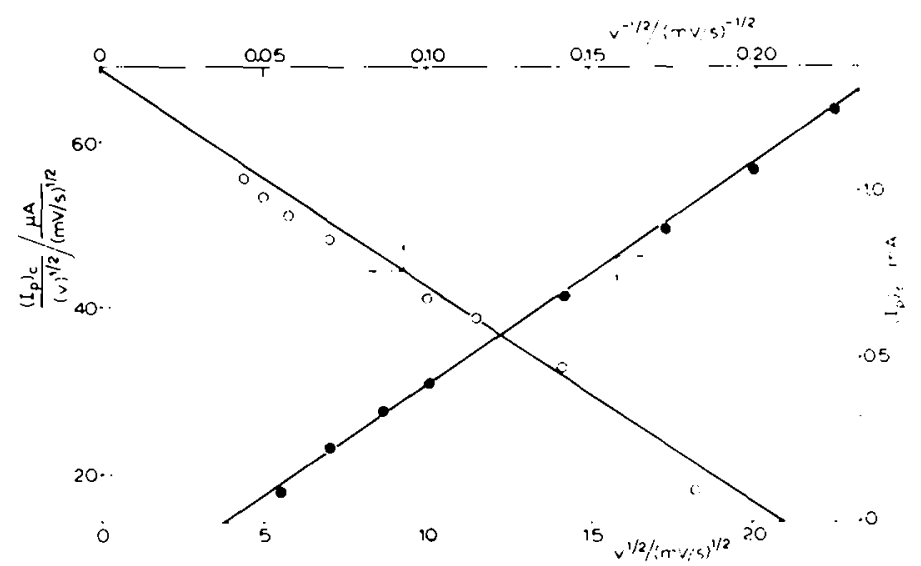

Fig. $18 .\left(I_{\mathrm{p}}\right)_{\mathrm{c}}$ vs. $\left(v^{1}\right)^{1 / 2}$ and $\left(I_{\mathrm{p}}\right)_{\mathrm{c}} /\left(()^{1 / 2}\right)^{1 / 2}$ vs. $\left(v^{\prime}\right)^{-1 / 2}$ plots at $24.8^{\circ} \mathrm{C} .5 .15 \times 10^{-2} . \mathrm{M} \mathrm{HCl}$, $1 \mathrm{M} \mathrm{NaClO}_{4}$.

files pertaining to solutions without initial $\mathrm{AuCl}_{4}^{-}$ion yield a linear $\left(I_{\mathrm{p}}\right)_{\mathrm{c}}$ vs. $v_{c}^{1 / 2}$ dependence only when the diffusion out of the interface of the reaction products anodically formed, is under control (Fig. 18), although the straight line does not intercept the origin of coordinates. The value of $\left(I_{\mathrm{p}}\right)_{\mathrm{c}}$ free of outward diffusion is obtained after extrapolation of $\left(I_{\mathrm{p}}\right)_{\mathrm{c}} / l_{\mathrm{c}}^{1 / 2}$ as a function of $1 / v_{\mathrm{c}}^{1 / 2}$ at $v_{\mathrm{c}} \rightarrow \infty$ (Fig. 18). The extrapolated $\left(I_{\mathrm{p}}\right)_{\mathrm{c}} / l_{\mathrm{c}}^{1 / 2}$ value is 1.7 times lower than the $\left(I_{\mathrm{p}}\right)_{\mathrm{a}} / v_{\mathrm{a}}^{1 / 2}$ ratio. This difference, in principle, can be attributed to the different diffusion coefficients of $\mathrm{Cl}^{-}$and $\mathrm{AuCl}_{4}^{-}$ions at the same ionic strength $[18,19]$.

The first portion of the cathodic potential scan also yields a Tafel relationship within a $0.1 \mathrm{~V}$ range with a slope of the order of $2.3(R T / F) \mathrm{V} /$ decade. These results also suggest the possible estimation of a common potential at the intersection of the anodic and cathodic E/og $v$ lines (Fig. 19) which is

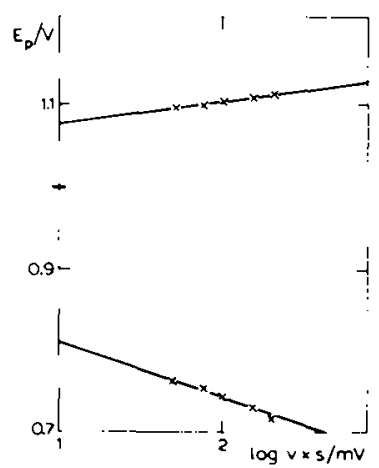

Fig. 19. Dependences of current peak potentials on log $v .4 .95 \times 10^{-3} \mathrm{M} \mathrm{HCl}, 1 \mathrm{M} \mathrm{NaClO}_{4}$, $26^{\circ} \mathrm{C}$. The two straight lines intercept at $1.0 \mathrm{~V}$. 
TABLE 1

Potentials defined at the interception of the anodic and cathodic Tafel lines

Solutions containing $1 \mathrm{M} \mathrm{NaClO}_{4}$

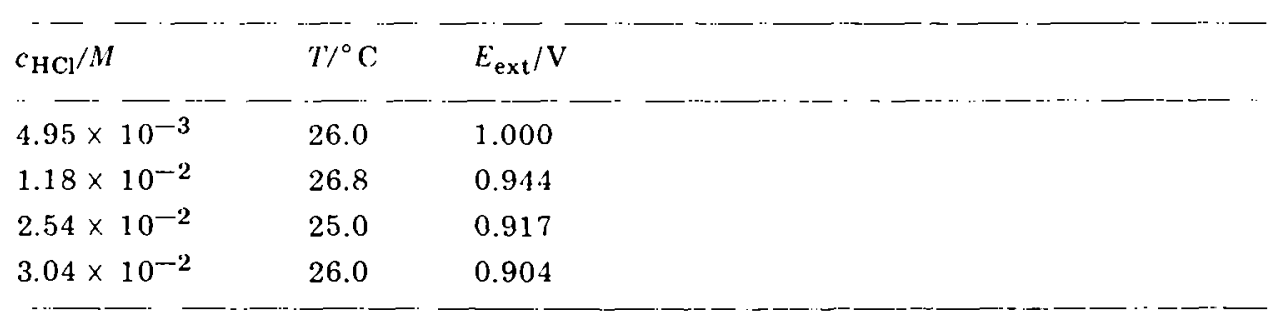

useful for overvoltage definition. Table 1 contains values of the extrapolated potentials, $E_{\text {ext }}$, at various $\mathrm{Cl}^{-}$ions concentration.

The passivity region

The passivity potential, $E_{\mathrm{pass}}$, defined at the break of the $E / I$ profile occurring at high anodic potential, depends linearly on the logarithm of $\mathrm{Cl}^{-}$ion concentration (Fig. 20) and $\mathrm{pH}$. At $25^{\circ} \mathrm{C}$ the following equation is obeyed

$E_{\text {pass }}=1.568+2.3(R T / F) \log c_{\mathrm{Cl}^{-}}-2.3(R T / F) \mathrm{pH}$

Accordingly, the passivity potential shifts towards more cathodic potentials as the $\mathrm{Cl}^{-}$ion concentration decreases and the $\mathrm{pH}$ increases approaching, thus, the potential of the electrodissolution current peak already described. Data previously reported by other authors about $E_{\mathrm{pass}}$ dependence on $c_{\mathrm{Cl}^{-}}$are also included in Fig. 20 [2].

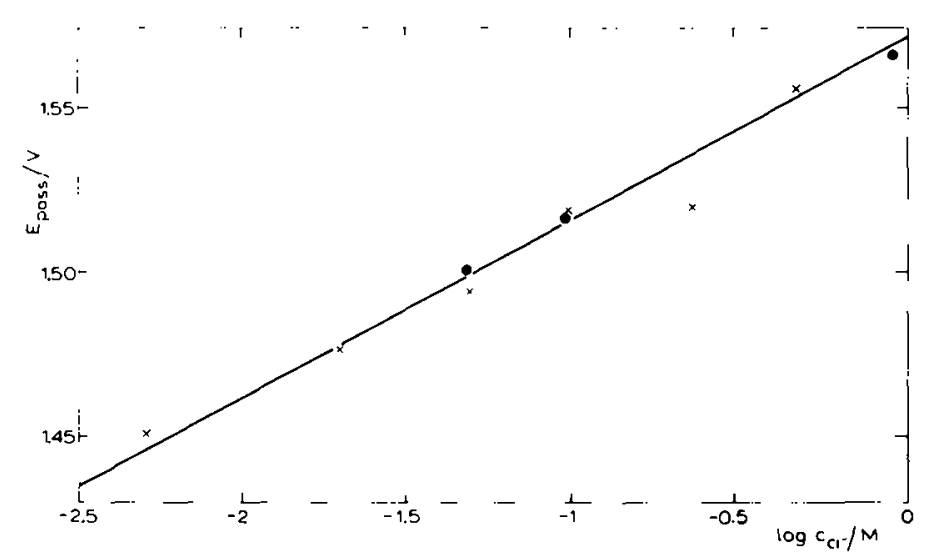

Fig. 20. Dependence of the passivity potential on chloride ion concentration at $25^{\circ} \mathrm{C}$. (๑) Present work; (x) from ref. [2]. 


\section{DISCUSSION}

The phenomenological aspects of Au electrodes in aqueous chloride solutions revealed the occurrence of various complex electrochemical reactions related to the active dissolution and the passivity of the metal. Their mechanistic interpretations can be attempted for the processes occurring both under stationary and non-stationary conditions. For the discussion of the probable reaction mechanisms it is convenient to survey certain aspects of Au electrodes such as those involving possible redox systems at equilibrium and the potential of zero charge of the metal.

\section{Preliminary considerations}

Ionic $\mathrm{Au}$ in aqueous chloride solutions may exist as $\mathrm{AuCl}_{2}^{-}$and $\mathrm{AuCl}_{4}^{-}$ complex ions, involving the following two equilibria:

$$
\mathrm{Au}+4 \mathrm{Cl}^{-}=\mathrm{AuCl}_{4}^{--}+3 e
$$

and

$$
\mathrm{AuCl}_{4}^{-}+2 \mathrm{Au}+2 \mathrm{Cl}^{--}=3 \mathrm{AuCl}_{2}^{-}
$$

The equilibrium constant of the heterogeneous process (3), at infinite dilution and $25^{\circ} \mathrm{C}$, obtained by extrapolation of formal equilibrium constants measured at $\mathrm{HCl}$ concentration between $0.2 \mathrm{M}$ and $2.0 \mathrm{M}$, is $1.8( \pm 0.3) \times 10^{-8}$. Therefore, the three possible redox couples at the interface are $\mathrm{Au} / \mathrm{AuCl}_{2}^{-}$, $\mathrm{Au} / \mathrm{AuCl}_{4}^{-}$and $\mathrm{AuCl}_{2}^{-} / \mathrm{AuCl}_{4}^{-}$, the first of which is considered as the potential determining one $[19,20]$. The $\mathrm{AuCl}_{2}^{-}$concentration depends on the $\mathrm{Cl}^{-}$ion concentration and on the total concentration of Au complex ions.

The potential of zero charge, $E_{z}$, of polycrystalline $A u$ in aqueous solutions depends on the ionic composition of the solution [21-24]. E, becomes more negative with the anion present in solution in the order $\mathrm{ClO}_{4}^{--}<\mathrm{SO}_{4}^{2-}<\mathrm{F}^{-}<\mathrm{Cl}^{-} \approx \mathrm{OH}^{-}<\mathrm{Br}^{-}<\mathrm{I}^{-}$. This is in reasonable agreement with the adsorbabilities of anions on gold 124-26]. Au electrodes in $\mathrm{HCl}$, $\mathrm{NaCl}$ and $\mathrm{KCl}$ aqueous solutions show that $E_{\text {, }}$, although it is independent of the cation, depends on the $\mathrm{Cl}^{--}$ion concentration according to [27]

$E_{\mathrm{z}}\left(\right.$ vs. NHE) $=-0.15+(2.3 R T / F) \log a_{\mathrm{C} 1}$.

At $\mathrm{pH}<9, E_{r}$ is $\mathrm{pH}$-independent and at $\mathrm{pH}>9$ it decreases linearly with $\mathrm{pH}$. Within the $\mathrm{Cl}^{-}$ion concentration and potential ranges prevailing in this work the Au electrode is always positively charged with respect to the solution. Then, it is quite likely that during the anodic runs the $\mathrm{Au}$ surface becomes practically saturated with adsorbed $\mathrm{Cl}{ }^{-}$ions.

The behaviour of $\mathrm{Au}$ anodes in $\mathrm{HClO}_{4}$ solutions depends strongly on the presence or absence of halide ions [9-13,28-30] particularly in the potential region between $0.9-1.3 \mathrm{~V}$ (vs. SCE), preceding the oxygen evolution region 
where the $\mathrm{OH}^{-}$ion plays an important role in the formation of a surface oxide layer. Au dissolves in aqueous $\mathrm{Cl}^{-}$ion containing solutions at $1.075 \mathrm{~V}$ while there is apparently no dissolution at $1.3 \mathrm{~V}$, but in $\mathrm{Br}^{--}$ion solutions it dissolves in the whole potential range [31]. The analysis of results revealed that there is no appreciable interference of the surface oxide formation in the active dissolution region, particularly at low $\mathrm{pH}$ and high $\mathrm{Cl}^{-}$ion concentrations, as it has been previously suggested [13].

\section{The possible mechanism of gold electrodissolution}

Experimental results indicate the anodic dissolution of $\mathrm{Au}$ in aqueous $\mathrm{Cl}^{--}$ solutions, is a reaction under intermediate kinetics. The degree of reversibility depends strongly on the state of the gold surface. The kinetic parameters previously derived for the activated process can be interpreted in terms of a reaction mechanism.

A simple reaction, such as a direct anodic metal dissolution, is immediately discarded to explain the anodic reaction, because the reaction depends strongly on the solution composition. A second possibility such as an initial $\mathrm{Cl}^{-}$ion discharge, is also, in principle, unlikely because this reaction occurs at potentials lower than $1.3 \mathrm{~V}$.

In acid solutions, $\mathrm{Cl}^{-\cdots}$ ions are specifically adsorbed on the positively charged Au electrode. Any reaction model for the dissolution process should, then, be discussed in terms of specifically adsorbed $\mathrm{Cl}^{-}$ions. A mechanism such as:

$\mathrm{Au}+\mathrm{Cl}^{-} \rightleftharpoons \mathrm{AuCl}_{\mathrm{ad}}^{-}$

$\mathrm{AuCl}_{\mathrm{ad}}^{-}+\mathrm{Cl}^{-} \rightleftharpoons\left(\mathrm{AuCl}_{2}^{-}\right)_{\mathrm{ad}}+e$

$3\left(\mathrm{AuCl}_{2}^{-}\right)_{\mathrm{ad}} \rightleftharpoons \mathrm{AuCl}_{4}^{-}+2 \mathrm{Au}+2 \mathrm{Cl}^{-}$

in the absence of any concentration polarization $\left(c_{\mathrm{Cl}^{--}}^{\mathrm{e}}=c_{\mathrm{Cl}^{-}}^{0}\right.$, e = electrode, $0=$ bulk of the solution), with step ( $5 a$ ) as a fast equilibrium and step (5b) as rate determining step, under the conditions that $\theta_{1}$, the degree of surface coverage by $\mathrm{AuCl}_{\mathrm{ad}}^{-}$, is much larger than that of $\left(\mathrm{AuCl}_{2}^{-}\right)_{\mathrm{ad}}$, implies that the pseudo-equilibrium constant of step (5a), $K_{5 a}$, is

$K_{5 \mathrm{a}}=\theta_{1} /\left(1-\theta_{1}\right) c_{\mathrm{Cl}}$

and the following expression for the anodic current density results:

$i_{\mathrm{a}}=F k_{5 \mathrm{~b}} 0_{1} c_{\mathrm{Cl}^{-}} \exp \left[\alpha_{\mathrm{a}} F E / R T\right]$

where $k_{5 \mathrm{~b}}$ is the formal rate constant of step (5b). Equation (7) involves two limiting cases. If $\alpha_{\mathrm{a}}=1 / 2$ and $\theta_{1} \rightarrow 1$, it becomes

$i_{\mathrm{a}} \approx F k_{5 \mathrm{~b}} c_{\mathrm{Cl}}-\exp [F E / 2 R T]$ 
and when $\theta_{1} \approx 0$, it follows that:

$i_{\mathrm{a}} \approx F k_{5 \mathrm{~b}}\left(c_{\mathrm{Cl}^{-}}\right)^{2} K_{5 \mathrm{a}} \exp [F F / 2 R T]$

Equations (8) and (9) agree only partially with the experimental results.

Based upon mechanism (5) another reaction pathway can be postulated by assuming that step (5b) is actually, the sum of an electrochemical and a chemical reaction, and that $\mathrm{AuCl}_{2}^{-\cdots}$ and $\mathrm{AuCl}_{4}$ ions participate in a homogeneous equilibrium:

$$
\begin{aligned}
& \mathrm{Au}+\mathrm{Cl}^{-} \rightleftharpoons \mathrm{AuCl}_{\mathrm{ad}}^{-} \\
& \mathrm{AuCl}_{\mathrm{ad}}^{-} \rightleftharpoons \mathrm{AuCl}_{\mathrm{ad}}+e \\
& \mathrm{AuCl}_{\mathrm{ad}}+\mathrm{Cl}^{-}=\left(\mathrm{AuCl}_{2}^{-}\right)_{\mathrm{ad}} \\
& 3\left(\mathrm{AuCl}_{2}^{-}\right)_{\mathrm{ad}} \rightleftharpoons \mathrm{AuCl}_{4}^{-}+2\left(\mathrm{AuCl}^{-}\right)_{\mathrm{ad}} \\
& \left(\mathrm{AuCl}_{2}^{-}\right)_{\mathrm{ad}} \rightleftharpoons \mathrm{AuCl}_{2} \\
& 3 \mathrm{AuCl}_{2}^{-} \rightleftharpoons \mathrm{AuCl}_{4}^{-}+2 \mathrm{Au}+2 \mathrm{Cl}
\end{aligned}
$$

Three different species can now be adsorbed on the electrode, namely,

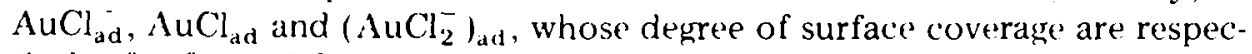
tively, $\theta_{1}, \theta_{2}$, and $\theta_{3}$. If the active dissolution involves a surface essentially saturated with the $\mathrm{AuCl}_{\mathrm{ad}}^{--}$species,

$1-0_{1}=\theta_{2}+\theta_{3} \approx 0$

and equilibria (10a) and (10b) are given by:

$K_{10 \mathrm{a}}=0_{1} /\left[1-\left(\theta_{1}+0_{2}+\theta_{3}\right)\right] c_{\mathrm{Cl}^{-}}$

$\left.K_{1 \mathrm{Ob}}=\left(O_{2} / 0_{1}\right) \exp \mid-F E / R T\right)$

Then, the anodic current, under steady conditions, when reaction (10c) is rate determining is:

$\left.i_{\mathrm{a}}=F K_{10 \mathrm{a}} K_{1 \mathrm{Ob}} k_{10 \mathrm{c}}\left(1-0_{1}\right)\left(c_{\mathrm{Cl}}\right)^{2} \exp \mid F E / R T\right]$

'This equation establishes, in principle, a second rate process with respect to $\mathrm{Cl}^{\cdots}$ ions and an anodic Tafel slope equal to $R T / F$. In equation (14) the

$\left(1-\theta_{1}\right)$ term may become a sensitive rate limiting factor.

If the reaction implies $\theta_{1} \rightarrow 1, \theta_{2} \ll 0_{1}$ and $K_{5 a} \gg 1$, eqn. (12) becomes:

$c_{\mathrm{C} 1-}\left(1-0_{1}\right) K_{10 \mathrm{a}}=0_{1} \approx 1$

Then, the stationary anodic current density is:

$i_{\mathrm{a}} \approx F K_{10 \mathrm{~b}} k_{10 \mathrm{c}} c_{\mathrm{C} 1}-\exp [F E / R T]$

Equation (16) corresponds to a 1 st order rate law with respect to $\mathrm{Cl}^{-}$ion 
concentration with an anodic Tafel slope equal to $R T / F$, in good correspondence with the experimental results. The assumption that $\theta_{1} \approx 1$ implies that $K_{10 a}$ is so large that even at very low $\mathrm{Cl}^{--}$ion concentrations, the condition of adsorbed $\mathrm{Cl}^{-}$ion saturation is practically always approached. If the concentration of $\mathrm{Cl}^{-}$ion at the reaction interface changes with potential, the ratio between $c_{\mathrm{C}]^{\circ}}^{\mathrm{O}}$ and $\mathrm{C}_{\mathrm{Cl}^{-}}^{\mathrm{e}}$ is:

$$
i_{\mathrm{d}} /\left(i_{\mathrm{d}}-i\right)=c_{\mathrm{Cl}}^{0}-/ c_{\mathrm{Cl}}^{\mathrm{e}}-
$$

where $i_{\mathrm{d}}$ is the limiting current density due to the transport process. Under these circumstances, the rate equation for a process such as $(10 \mathrm{c})$ results:

$i_{\mathrm{a}}=i_{0}\left[\left(1-i_{\mathrm{a}} / i_{\mathrm{d}}\right) \exp \left(\alpha_{\mathrm{a}} F \eta / R^{\prime} T\right)\right]$

$i_{0}$ being the exchange current density and $\eta$ the overpotential defined with respect to the potential at which experimentally $i=0$.

At high positive potentials eqn. (18) implies a stationary mass transport limiting current as $E \rightarrow \infty,\left(c_{\mathrm{Cl}_{-}}^{\mathrm{e}} \rightarrow 0\right)$. This limiting current density should change linearly both with the square root of the rotation speed at the rotating disc electrode and $\mathrm{Cl}^{-}$ion concentration. The corresponding potentiodynamic response is an anodic current peak whose height depends linearly both on the square root of the potential sweep rate and $\mathrm{Cl}^{-}$ion concentration and whose current peak potential changes linearly with $\log v$.

The postulated reaction mechanism involves the participation of the adsorbed $\mathrm{AuCl}_{2}^{-}$ion in the r.d.s., while the formation of the $\mathrm{AuCl}_{4}^{-}$ion results from a heterogeneous chemical equilibrium essentially similar to that measured through galvanic cells [27]. Accordingly when $c_{\mathrm{Cl}}^{0} \rightarrow-\rightarrow$, the $\mathrm{AuCl}_{2}^{-}$species should occur as the main reaction product. Therefore, the heterogeneous equilibrium determines the magnitude of the $\mathrm{Au}(\mathrm{I}) / \mathrm{Au}(\mathrm{III})$ concentration ratio in solution [2], and it also explains the well-known gold sludge formation at the anode.

\section{TABLE 2}

Diffusion coefficients derived from RDE data

\begin{tabular}{|c|c|c|c|}
\hline$T 7^{\circ} \mathrm{C}$ & Solution composition & $10^{5} \times D / \mathrm{cm}^{2} \mathrm{~s}^{-1}$ & . \\
\hline 25.0 & $\begin{array}{l}x M \mathrm{HCl}+1 M \mathrm{NaClO}_{4} \\
\left(2 \times 10^{-3} \leqslant x \leqslant 10^{-1}\right)\end{array}$ & 1.47 & \\
\hline 25.8 & $\begin{array}{l}5.3 \times 10^{-2}+ \\
1 \mathrm{M} \mathrm{NaClO}_{4}\end{array}$ & 1.50 & \\
\hline 45.0 & $\begin{array}{l}5.3 \times 10^{-2} \\
1 \mathrm{M} \mathrm{NaClO}_{4}\end{array}$ & 1.95 & \\
\hline 64.6 & $\begin{array}{l}5.3 \times 10^{-2}+ \\
1 \mathrm{M} \mathrm{NaClO}_{4}\end{array}$ & 2.69 & \\
\hline
\end{tabular}


The diffusion coefficient of the $\mathrm{Cl}^{-}$ion

'The mass transport anodic limiting current density determined with the RDE actually involves a null concentration of $\mathrm{Cl}^{-}$ion at the electrode surface. Under those circumstances if reaction (10f) is a fast process, the $\mathrm{AuCl}_{4}^{-}$ ion becomes the main reaction product at the interface. Therefore, the diffusion coefficient of $\mathrm{Cl}^{-}$ion can be evaluated from the limiting current density, through, for instance, Levich's equation [30], taking the number of charges per mol of reacting species, equal to 0.75 . The calculated diffusion coefficient of $\mathrm{Cl}^{-}$ion, $D$, (Table 2 ) agrees with those previously reported [31].

\section{The passivity of gold}

As clearly seen both in the RDE and in the potentiodynamic runs, a definite passivity occurs at $E>1.17 \mathrm{~V}$. To determine the formation of the passivating film at potentials close to the passivity potential. $E_{\text {pass }}$, attention should be paid to the current decrease after the current peak recorded during the voltammetric runs. The current decay at $E_{\mathrm{p}} \leqslant E<E_{\text {pass }}$ follows (Fig. 21) the simple law expected for a diffusion control reaction [32]:

$I_{\mathrm{a}}=\mathrm{A}-\mathrm{B} t^{1 / 2}$

where $I_{\mathrm{a}}$ is the anodic current at time $t$ and $\mathrm{A}$ and $\mathrm{B}$ are constants. Therefore any interference of passivity in the active dissolution region at $\mathrm{pH}<7$ is, in principle, unlikely. Apparently the onset of passivity requires $c_{\mathrm{Cl}^{--}}^{\mathrm{e}} \rightarrow 0$. Then, the process corresponds to that exhibited by $\mathrm{Au}$ anodes in acid aqueous solutions containing either $\mathrm{ClO}_{4}^{-\cdots}$ or $\mathrm{SO}_{4}^{2-}$ ions $[33,34]$. The dependence of $E_{\text {pass }}$ observed with $\mathrm{Au}$ electrodes on the $\mathrm{Cl}^{-}$ion concentration and $\mathrm{pH}$ is very close to that observed for $E$,. This correspondence suggests a competitive effect be-

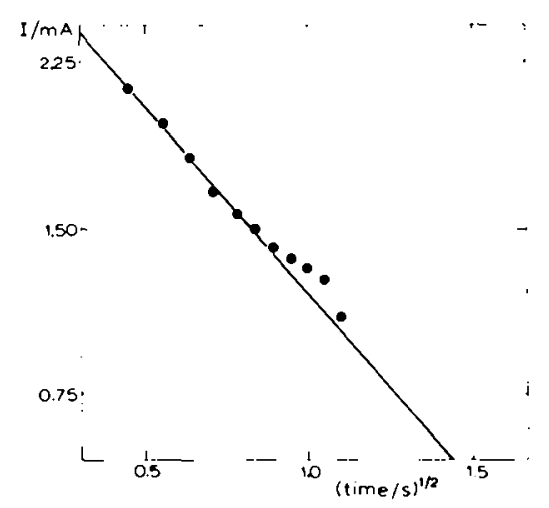

Fig. 21. Plot of an anodic voltammogram run with a single linear potential sweep taking into account the current decay when the current peak potential is exceeded. This plot corresponds to a voltammogram obtained with a solution $5.30 \times 10^{--2} \mathrm{M} \mathrm{HCl}, 1.20 \times 10^{-3}$ $M \mathrm{HAuCl}_{4}, 1 \mathrm{M} \mathrm{NaClO}_{4} ; 25^{\circ} \mathrm{C}$. 
tween $\mathrm{OH}^{-}$and adsorbed $\mathrm{Cl}^{-\cdots}$ ions at the reaction interface. Apparently, the former species only reacts at the electrode surface after the adsorbed $\mathrm{Cl}^{-}$ion is depleted there.

On the other hand, the passivity potential lies close to the oxygen electrode potential and both exhibit a similar $\mathrm{pH}$ dependence.

Therefore, the anodic behaviour of $\mathrm{Au}$ in $\mathrm{Cl}^{-}$ion containing solutions can be depicted as follows. At $E>E$, the $\mathrm{Cl}^{-}$ions are specifically adsorbed on the Au surface; when $E>0.9 \mathrm{~V}$, Au dissolves anodically. In the range $0.9 \leqslant E \leqslant E_{\text {pass }}$, the $\mathrm{Cl}^{-}$concentration at the interface diminishes with potential until the anodic dissolution becomes diffusion controlled. When $E=E_{\text {pass }}$, the $c_{\mathrm{Cl} l^{-}}^{\mathrm{e}} \rightarrow 0$ and at $E>E_{\mathrm{pass}}$ either the $\mathrm{OH}^{-}$ion or $\mathrm{H}_{2} \mathrm{O}$ discharge yields a surface oxide which passivates the metal.

\section{Reproduction of the anodic voltammogram}

The calculation of an experimental voltammogram including both the anodic dissolution and passivation regions, can be made by means of an equation containing two terms, one for the irreversible anodic dissolution under diffusion control and another taking into account passivation:

$I_{\mathrm{a}}=\left(I_{\mathrm{d} \text { iss }}\right)_{E<E^{\prime}}+\left(I_{\mathrm{ox}}\right)_{E}>E^{\prime \prime}$

where

$I_{\mathrm{diss}}=602 A(1-0) n\left(\alpha_{\mathrm{a}} n_{\mathrm{a}}\right)^{1 / 2} D^{1 / 2} v^{1 / 2} c_{\mathrm{C} 1}^{0}-\psi(t)$

and

$\left.I_{\mathrm{ox}}=\left(I_{\mathrm{ox}}\right)_{0} A(1-\theta) \exp \left[F\left(E_{\mathrm{i}}+v t\right) / R T\right] \exp \mid-f \theta\right]$

The current is given in $\mathrm{A} ; A$ is the electrode area; $\psi(t)$ is the current function and $E_{\mathrm{i}}$ is the initial potential. Equation (22) contains a Temkin factor, $f$, and 0 the degree of surface coverage by the oxide. Equation (21) contains the term $(1-\theta)$ to express the actual electrode area. To obtain $I_{\mathrm{ox}}$ one should express $I_{\mathrm{ox}}$ as a function of $\theta$ and time, $t$ :

$I_{\mathrm{ox}}=A k_{0} \mathrm{~d} 0 / \mathrm{d} t$

where $k_{0}$ is the amount of oxide required to form a monolayer film. Then,

$A(\mathrm{~d} \theta / \mathrm{d} t)=\left(I_{\mathrm{ox}} / k_{0}\right)(1-0) \exp \left[\alpha_{\mathrm{a}} F\left(E_{\mathrm{i}}+v t\right) / R T\right] \exp [-f \theta]$

Equation (24) is solved numerically to yield $\theta=\theta(t)$. The instantaneous values of $\theta(t)$ in eqn. (22) give $I_{\mathrm{ox}}=I_{\mathrm{ox}}(E)$. If $E^{\prime}$ represents the potential where the surface starts to be covered with the oxide layer, a complete surface oxidation is achieved at $E_{\text {pass. }} E^{\prime}$ can be estimated from Fig. 21 , as the potential where a deviation of experimental data from the theoretical $I / t^{1 / 2}$ plot is observed. Experimental and theoretical data are shown in Fig. 22. Equation (24) predicts 

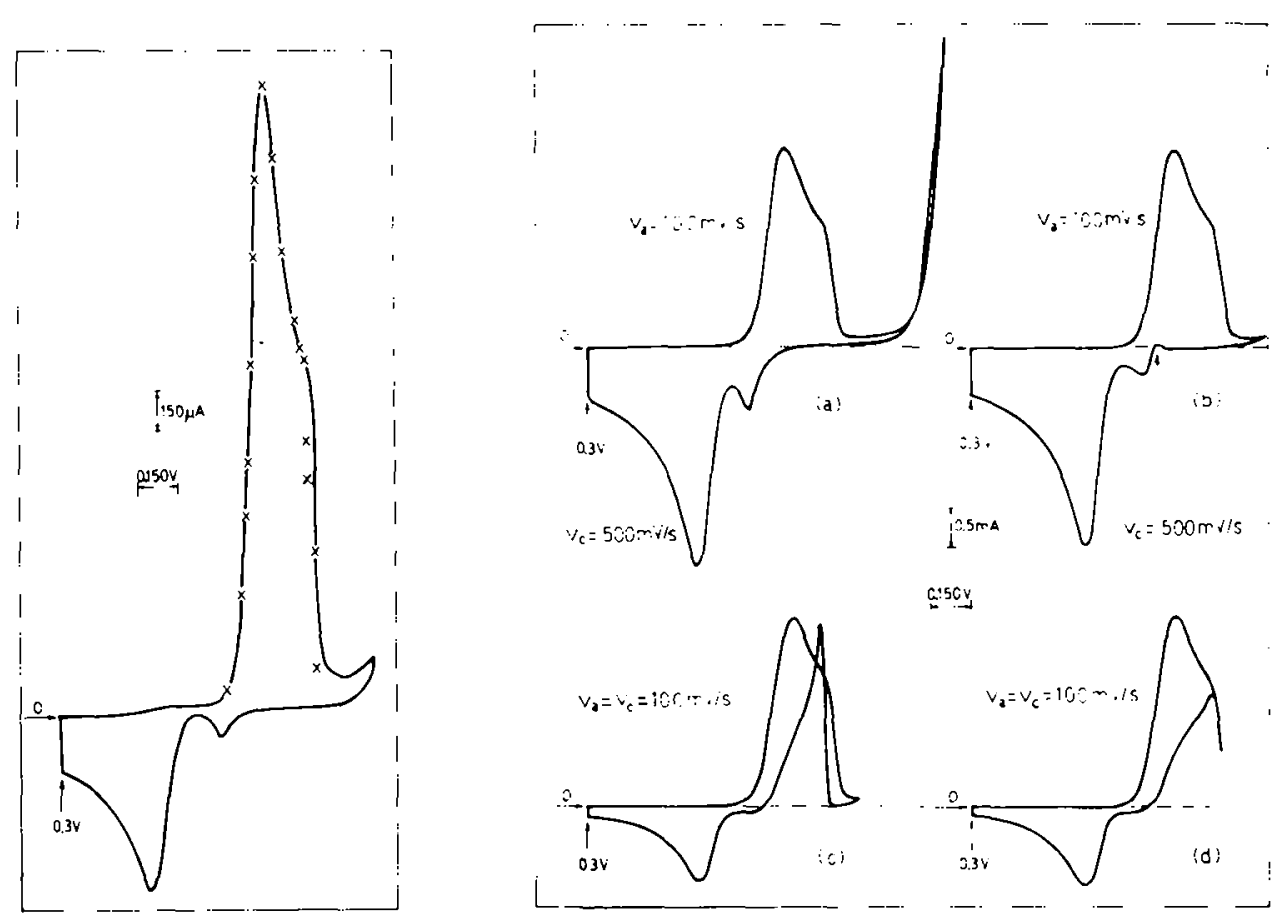

Fig. 22. Comparison of an anodic voltammogram with results obtained with e(jn. (24) (x). Solution composition: $5.30 \times 10^{-2} . \mathrm{M} \mathrm{HCl}, 1.20 \times 10^{-3} . \mathrm{MHACl}_{4}, 1 . \mathrm{H} \mathrm{NaClO}_{4} ; 25^{\circ} \mathrm{C}$.

Fig. 23. Voltammograms run with different potential amplitudes by changing the anodic limit of potential. $1.18 \times 10^{-2} \mathrm{M} \mathrm{HCl}, 1 \mathrm{M} \mathrm{NaClO}_{4} ; 64.0^{\circ} \mathrm{C}$.

$I_{\mathrm{ox}}=0$ when $\theta=1$. This situation, however, is not attained because of the resistivity due to the passive film and the competition between the film formation and its chemical dissolution. The latter is appreciably enhanced in the presence of $\mathrm{Cl}^{-}$ions as seen, for instance, in Fig. 23 where the amount of cathodic charge related to the surface oxide electroreduction at $0.9 \mathrm{~V}$ is appreciably reduced and the anodic current recorded at the initiation of the cathodic sweep increases when the cathodic potential sweep rate decreases (Figs. 23b and c). These effects also depend on the anodic limit of the potential sweep.

\section{Probable mechanism of $A u(I I I)$ electrodeposition on $A u$}

In principle, one might expect the occurrence of two electroreduction processes, with the participation of either $\mathrm{AuCl}_{2}^{-}$ion or $\mathrm{AuCl}_{4}^{-}$ion depending on the $\mathrm{Cl}^{-}$concentration. With concentrated $\mathrm{HCl}$ solutions, there is a clear evidence of a cathodic current peak at $1 \mathrm{~V}$, related to the electroreduction of the $\mathrm{AuCl}_{2}^{-}$species together with a second cathodic current peak, at $0.675 \mathrm{~V}$, 
which corresponds to the $\mathrm{AuCl}_{4}^{--}$discharge. The $\mathrm{Au}(\mathrm{I})$ electroreduction current is more easily detected during the voltammetric runs, if the cathodic potential scan is initiated at anodic potentials where the $\mathrm{Cl}^{-}$concentration at the interface is still close to the bulk concentration.

When equilibrium (10f) is shifted to the right the main cathodic current is related to $\mathrm{AuCl}_{4}^{-}$discharge. This reaction can be interpreted with the same reaction pathway already discussed for the anodic process. Under potentiodynamic conditions, however, at the initiation of the cathodic potential scan, the energetic and structural configurations of the reaction interface are different from those prevailing during the anodic potential scan, depending on the starting cathodic potential.

The electrodeposition of $\mathrm{Au}$ is a complex process implying a change of the solid metal activity, which is difficult to control during the cathodic reaction. Under potentiodynamic conditions, it exhibits the characteristics of an irreversible reaction, as the potential of the current peak changes linearly with $\log v$. The slope of the line is either $R T / F$ or $2 R T / F$, depending on the experimental conditions. The peak potential $\left(E_{\mathrm{p}}\right)_{\mathrm{c}}$ is more cathodic the higher the $\mathrm{Cl}^{-}$ion concentration.

On the other hand, the larger the time elapsed between the anodic and the cathodic processes, the smaller the amount of charge taking part in the cathodic reaction because part of the anodic product diffuses out. These results, however, contrarily to previously reported interpretation [35], exhibit neither any appreciable electrode roughness increase, nor any reversible type of process. The $\mathrm{Cl}^{-}$ion concentration has quite a marked influence on the cathodic process, as previously shown by interrupting the anodic potential scan at different potentials in the region of the anodic current peak potential. The narrower the potential amplitude swept $\left(c_{\mathrm{Cl}_{1}-}^{\mathrm{e}} \rightarrow \mathrm{c}_{\mathrm{Cl}}^{\mathrm{o}}\right.$ ) , the more positive the cathodic current peak potential becomes. These facts explain the apparent reversibility of the cathodic process observed in those runs, made at a constant $v_{\mathrm{a}}$ and changing $v_{c}$. The reversible behaviour comes from opposite effects. Thus, when $v_{\mathrm{c}}$ increases, although $\left(E_{\mathrm{p}}\right)_{\mathrm{c}}$ becomes more cathodic with $v_{\mathrm{c}}$, the local $\mathrm{Cl}^{-}$ion concentration diminishes and, concomitantly the cathodic peak poten. tial results more anodic.

The limiting Tafel slopes obtained from the initial portion of the cathodic voltammograms, agree with those derived from the $E / \log v$ plots. When the anodic reaction behaves reversibly the cathodic Tafel slope is $2 R T / F$. Otherwise, when the anodic reaction appears as irreversible, the cathodic Tafel slope is $R T / F$. These facts can be tentatively explained in terms of the reaction pathway already discussed for the anodic process. During the cathodic reaction the metal surface is still covered with adsorbed $\mathrm{Cl}^{-}$ions since the potentials swept are still more positive than $E_{\mathrm{z}}$.

The cathodic reaction like the anodic one strongly depends on the ionic composition of the solution and on the characteristics of the base metal. Nevertheless, the latter seems to be much more important than any change of the electrode roughness. 


\section{ACKNOWLEDGEMENTS}

This work is part of the research program of the Electrochemistry Division of INIFTA, sponsored by the Lniversidad Nacional de La Plata, The Consejo Nacional de Investigaciones Cientificas y Tecnicas and the Comision de Investigaciones Cientificas de la Provincia de Buenos Aires. J.H.G. is with a leave of absence of the Universidad del Quindio. Colombia and thanks the Organization of American States for the fellowship granted.

\section{REFERENCES}

1 E. Wolhwill, Electrochem. Ind., 1 (1903) 157:2 (1904) 221:6(1908) 450 .

2 G. Just and R. Lansberg, Electrochim. Acta, 9 (1964) 817 ; Z. Phys. Chem., 226 (1964) 183.

3 J.N. Gaur and G.M. Schmid, J. Electroanal. Chem., 24 (1970) 279.

4 J. Cathro and D.F.A. Kuch, J. Electrochem. Soc., 111 (1964) 1.116.

5 D.M. MacArthur, J. Electrochem. Soc., 119 (1972) 673.

6 J. A. Harrison and J. Thompson, J. Flectroanal. Chem., 40(1972) 113.

7 T. Takamura, K. Takamura and E. Yeager, J. Electroanal. Chem., 29 (1971) 279.

8 Nguyen Van Huong, M. Petit and J. Clavilier, C.R. Acad. Sci. (Paris), 278 (1974) 825.

9 S.H. Cadle and S. Bruckenstein, J. Electroanal. Chem., 18 (1973) 325.

10 A. Hamelin and J.P. Bellier, J. Electroanal. Chem., 11 (1973) 179.

11 S.M. Brummer and A.C. Makrides, J. Electrochem. Soc., $111(1964) 1122$.

12 S.B. Brummer, J. Electrochem. Soc., $112(1965) 633$.

13 K. Ogura, S. Haruyama and K. Nagasaki, J. Flectrochem. Soc., 118 (1971) 531.

14 M.E. Martins, G. Paús, A.J. Calandra and A.J. Arvia, Anales Asoc. Quim. Arg., 57 (1969) 91.

15 Th. Heumann and H.S. Panesar, Z. Phys. Chem., 229 (1965) 84.

16 C. Ferro, A.J. Calandra and A.J. Arvia, J. Electroanal. Chem., 55 (1974) 291

17 D.H. Evans and J.J. Lingane, J. Electroanal. Chem., 8 (196.1) 173.

18 R.B. Simpson, R.L. Evans and H.A. Saroff, J. Amer. Chem. Soc., 77 (1955) 1438.

19 J.J. Lingane, J. Flectroanal. Chem., 4 (1962) 332.

20 N. Bjerrum, Bull. Soc. Chim. Belges, $57(1948) 432$.

21 E.K. Vestren, V.I. Likhtman and P.A. Rehbinder, Dokl. Akad. Nauk SSSR, 107 (1956) 106.

22 T.N. Voropaeva, B.V. Deryagin and B.N. Kabanov, Kolloid. Z., 24 (1962) 396.

23 T.N. Andersen, R.S. Perkins and H. Eyring, J. Amer. Chem. Soc., 86 (1964) 4496.

24 D.D. Bode, T.N. Andersen and H. Fyring, J. Phys. Chem., 71 (1972) 792.

25 J.P. Carr and N.A. Hampson, J. Electrochem. Soc., 119 (1972) 325.

26 M. Brzostowska, Roczn. Chem., 46 (1972) 2345.

27 K.I. Nominiski and E.M. Lazarova, Sov. Electrochem., 9 (1973) 648.

28 H.A. Laitinen and M.S. Chao, J. Electrochem. Soc., $108(1961) 726$.

29 R. Woods, Electrochim. Acta, 14 (1969) 533;16 (1971) 655.

30 B. Levich, Physicochemical Hydrodynamics, Prentice-Hall, Englewood Cliffs, N.J., 1962.

31 J.N. Gaur and G.M. Schmid, J. Electroanal. Chem., 24 (1973) 279.

32 R.N. Adams, Electrochemistry at Solid Electrodes, M. Dekker, New York, 1969.

33 M.D. Goldshtein and T.I. Zalkind, Sov. Electrochem., 9 (1973) 673.

34 C. Ferro, A.J. Calandra and A.J. Arvia, J. Electroanal. Chem., 59 (1975) 239.

35 D.H. Evans and J.J. Lingane, J. Electroanal. Chem., 6 (1963) 1. 